\title{
Non causa pro causa: o voto de direita e esquerda no Brasil
}

Frederico Batista Pereira ${ }^{1}$ (D)

A maioria dos estudos sobre o voto no Brasil converge no diagnóstico de que a escala direita-esquerda não está associada à escolha do eleitorado. Todavia, parte da literatura frequentemente ignora ou desafia tal consenso. Para resolver essa questão, este artigo replica e reanalisa dados de opinião pública utilizados por estudos como evidência de que o eleitorado votaria sim com base na escala direita-esquerda (19892014). Os resultados indicam que tais estudos incorrem em equívocos metodológicos que invalidam suas conclusões. A associação estatística entre ideologia e voto é baixa de modo geral e apenas alta em um grupo reduzido de pessoas politicamente mais sofisticadas. Por fim, a análise de dados de painel não encontra evidência de que a associação indique uma relação causal mesmo entre os(as) mais sofisticado(as). Em suma, é preciso buscar novos horizontes na explicação do voto no Brasil.

Palavras-chave: eleições; ideologia; sofisticação política; comportamento eleitoral; análise de survey

A história do pensamento democrático - incluindo parte da ciência política contemporânea - é marcada por um vício em teorias românticas. Como em todo vício, o primeiro passo para a recuperação é admitir que temos um problema.

(Achen e Bartels, Democracy for realists, 2017, p. 20)

\section{Introdução}

De tempos em tempos ressurge na ciência política brasileira a tese de que o eleitorado se orienta pelos termos direita e esquerda ao votar. Contrariando vasta literatura que evidencia as dificuldades do eleitorado brasileiro em compreender e utilizar tais termos, pelo menos três estudos notáveis propõem que a ideologia, representada na escala direitaesquerda, seria uma causa relevante do voto para presidente no eleitorado brasileiro. Singer (1999, p. 47) considera "inexplicável" que os estudos do voto anteriores ao seu tenham deixado de considerar a clivagem direita-esquerda como manifestação ideológica do eleitorado. Holzhacker e Balbachevsky (2007) qualificam o argumento dizendo que a

\footnotetext{
${ }^{1}$ Department of Political Science and Public Administration, University of North Carolina at Charlotte. Charlotte (NC), EUA. E-mail: <fbatist1@uncc.edu>.
} 
clivagem direita-esquerda é um determinante do voto em algumas eleições, mas não em outras. Mais recentemente, Izumi (2019) propõe uma correção à escala direita-esquerda que, supostamente, revelaria o efeito da clivagem sobre o voto para presidente, independentemente dos níveis de sofisticação política dos eleitores.

Uma vez que os dados das pesquisas de opinião utilizados pela literatura se encontram disponíveis para o uso público, o presente artigo revisita a questão do voto de direita ou esquerda por meio do processo de replicação e reanálise dos dados (King, 1995) ${ }^{2}$. Assim, nas linhas que seguem, eu mostro que não há evidências convincentes de que o eleitorado brasileiro se oriente com base nos termos "direita" e "esquerda" para escolher o presidente. A primeira seção do artigo, "Preâmbulo: o suposto dissenso sobre o tema", demonstra que, ao contrário do que parte da literatura sugere, não há dissenso ou debate no que se refere às evidências sobre o voto ideológico, uma vez que a esmagadora maioria dos estudos empíricos não encontra associação sistemática entre ideologia e voto. As seções seguintes, "Estudo 1: Direita e esquerda no eleitorado brasileiro", "Estudo 2: A identidade ideológica do voto em Lula" e "Estudo 3: Ideologia e sofisticação política", reanalisam os dados dos três estudos existentes a favor do voto ideológico no Brasil e identificam um conjunto de problemas que os levam a conclusões equivocadas. Em consonância com a parte da literatura, a reanálise dos dados revela que: 1 ) a proporção de respostas na escala direitaesquerda é baixa, o que tem consequências metodológicas e substantivas que a literatura ignora (problema da não resposta); 2) a probabilidade de resposta na escala direita-esquerda está associada à sofisticação política, o que torna os(as) respondentes analisados(as) diferentes da totalidade do eleitorado (viés de seleção); 3) a associação estatística previamente encontrada é sobrestimada devido à omissão de variáveis de controle relevantes (correlação espúria ou viés por omissão de controles); 4) a associação estatística entre a escala direita-esquerda e o voto é forte apenas entre eleitores(as) politicamente mais sofisticados(as) (efeito heterogêneo); e 5) a associação estatística entre escala direitaesquerda e voto não indica causalidade (confusão entre correlação e causação), de acordo com dados de painel analisados na seção "Correlação e causalidade".

Nas "Considerações finais", especula-se sobre as razões pelas quais uma teoria moribunda como a do voto de direita ou esquerda insiste em retornar ao debate no Brasil. Eu discuto a acusação de elitismo que o estudo da sofisticação política recebe na ciência política brasileira e demonstro que ela ora reflete obscurantismo, ora reflete uma agenda antissociológica infértil para o estudo do comportamento eleitoral.

\footnotetext{
2 Todos os dados utilizados neste artigo estão disponíveis publicamente em diferentes repositórios. O artigo apenas replica análises de alcance nacional. Os códigos com os modelos completos (para o Stata 13.1) podem ser encontrados em:

<https://dataverse.harvard.edu/dataset.xhtml?persistentId=doi:10.7910/DVN/OXNV8P>. Acesso em: 1 out. 2019.
} 


\section{Preâmbulo: o suposto dissenso sobre o tema}

Parte da literatura sobre comportamento eleitoral no Brasil parece tratar a questão de ser ou não o voto para presidente guiado pelos rótulos "direita" e "esquerda" como ponto controverso ou mal resolvido no campo (Spinelli, 2000, p. 156; Bonifácio, Casalecchi e Sandes-Freitas, 2014, p. 299; Izumi, 2019, p. 33). No entanto, um exame mais completo da produção empírica no campo do comportamento eleitoral mostra o contrário: a quantidade de estudos cujas análises reportam resultados nulos sobre a relação entre a escala direita-esquerda e o voto para presidente é consideravelmente maior do que os estudos com resultados em favor da tese. A Tabela 1 lista os estudos do período pósredemocratização que reportam análises de pesquisas de opinião pública. Os únicos estudos que apresentam resultados indicando que a clivagem direita-esquerda se associa ao voto são os de Singer (1999), Holzhacker e Balbachevsky (2007) e Izumi (2019). Do outro lado, um total de mais de 20 estudos apresentam resultados empíricos sugerindo que a clivagem direita-esquerda tem efeitos ambíguos ou nulos sobre o voto para presidente ${ }^{3}$.

\section{Tabela 1 \\ Respostas de artigos testando se a localização dos eleitores no espaço direita-esquerda se associa o voto para presidente no Brasil}

\begin{tabular}{|l|l|}
\hline Há evidências & \multicolumn{1}{c|}{ Não há evidências } \\
\hline & 1. Reis e Castro (1992) \\
& 2. Castro (1994) \\
& 3. Reis e Castro (2000) \\
& 4. Almeida (2001) \\
& 5. Carreirão (2002a) \\
& 6. Carreirão (2002b) \\
& 7. Carreirão (2004) \\
& 8. Carreirão (2007) \\
& 9. Rennó (2006) \\
1. Singer (1999) & 11. Ames e Smith (2010) \\
2. Holzhacker e Balbachevsky (2007) & 12. Telles e Storni (2011) \\
3. Izumi (2019) & 13. Batista Pereira (2013) \\
& 14. Batista Pereira (2014) \\
& 15. Batista Pereira et al. (2014) \\
& 16. Bonifácio, Casalecchi e Sandes-Freitas \\
& 17. Nicolau (2014) \\
& 18. Amaral e Ribeiro (2015) \\
& 19. Oliveira e Turgeon (2015) \\
& 20. Zechmeister (2015) \\
& 21. Silva (2017) \\
\hline
\end{tabular}

Fonte: Elaboração própria.

\footnotetext{
3 Em Nicolau (2014) e Amaral e Ribeiro (2015), as variáveis de identificação ideológica apresentam coeficientes estatisticamente significativos, mas apenas em comparação com a categoria de "não resposta" usada como base. Os coeficientes não são estatisticamente diferentes entre si, o que indica que eleitores de direita, centro e esquerda não se diferenciam.
} 
A ideia de que não existe consenso sobre o assunto parece se basear na premissa de que a posição minoritária, de alguma maneira, apresenta evidências claras, as quais a literatura oposta e majoritária não é capaz de contestar. No entanto, o exame mais cuidadoso da literatura mostra que esse não é o caso. Embora a maioria dos estudos do campo que nega a associação não aborde diretamente a evidência apresentada pela minoria, há estudos que tratam mais diretamente de algumas limitações importantes nas evidências apresentadas em favor do voto ideológico (Carreirão, 2002b; Bonifácio, Casalecchi e SandesFreitas, 2014). As seções seguintes discutem e investigam de forma direta vários aspectos das análises dos três estudos em questão que os levam a apresentar resultados enviesados e a interpretar equivocadamente os resultados encontrados.

\section{Estudo 1: Direita e esquerda no eleitorado brasileiro}

O primeiro estudo a propor a relevância do voto com base nos termos direita e esquerda no Brasil é o de Singer (1999). O livro é um esforço ambicioso e de alcance amplo (com pesquisas de opinião nacionais e estaduais) e oferece reflexões importantes sobre o processo eleitoral brasileiro após a redemocratização. $O$ autor afirma que a literatura anterior estaria equivocada ao pretender compreender a lógica do comportamento eleitoral no Brasil sem a escala direita-esquerda (p. 47). O estudo propõe que, embora boa parte dos eleitores não tenha um entendimento profundo do significado dos termos direita e esquerda, o eleitorado teria imagens gerais ou vagas dessas categorias que orientariam a escolha do candidato a presidente. O autor analisa dados nacionais sobre a eleição presidencial de 1989 e dados de São Paulo sobre a eleição de 1998 (além de outras pesquisas de opinião que não perguntavam sobre o voto). Segundo Singer, "quando comparada a outras variáveis preditivas do voto naquelas ocasiões, a identificação ideológica revelou-se das mais fortes" (p. 17) ${ }^{4}$.

Singer utiliza dados de pesquisas de opinião nacionais para mostrar que a autolocalização ideológica está associada à escolha para presidente. Por meio de tabulações, o trabalho mostra que eleitores(as) que se dizem de esquerda votam em maiores proporções em candidatos(as) de esquerda, enquanto eleitores(as) de direita tendem a votar em candidatos(as) de direita. Para 1989, por exemplo, essa diferença é de, em média, 40\% para o primeiro turno (Singer, 1999, p. 82) e de $50 \%$ para o segundo turno (p. 84) 5 . O autor também utiliza tabulações e correlações bivariadas para mostrar que outras variáveis (como escolaridade, opiniões políticas e preferência partidária) se associam ao voto. O autor conclui que "(...) o eleitor soube, em sua grande maioria, localizar-se no contínuo esquerda-direita

\footnotetext{
${ }^{4}$ Para revisões mais completas do livro de Singer, ver Reis (2000a), Carreirão (2002b) e Bonifácio, Casalecchi e Sandes-Freitas (2014).

${ }^{5}$ Valores obtidos por meio da média ponderada entre as diferenças de frequência entre eleitores de esquerda e de direita.
} 
e esse posicionamento esteve fortemente associado à escolha do candidato em quem votar" (p. 17).

Reis (2000a) é o primeiro a questionar a validade de tais conclusões, apontando para a taxa elevada de não resposta (para 1989, cerca de 20\%, de acordo com o Anexo do livro) e sua alta relação com a escolaridade. Tal padrão revelaria o forte componente cognitivo da tarefa de se localizar na escala direita-esquerda. Mais tarde, Carreirão (2002b) utiliza os mesmos dados e confirma as suspeitas de Reis. A escolaridade está relacionada à resposta correta à pergunta sobre o significado dos termos direita e esquerda e sobre a probabilidade de resposta na escala. Reis também aponta para o problema dos efeitos heterogêneos. Uma vez que o voto ideológico teria um forte componente cognitivo, exigindo dos eleitores certo nível de entendimento sobre o significado das categorias direita e esquerda, seria de esperar que as associações encontradas fossem apenas observadas entre eleitores(as) mais sofisticados(as) que compreendessem os significados dos termos. O artigo de Carreirão (2002b) também confirma tal suspeita ao testar a associação entre ideologia e voto para diferentes níveis de escolaridade. No entanto, Carreirão usa associações gamma com a amostra dividida, e não há, portanto, um teste formal da diferença entre as associações observadas. Além disso, Carreirão segue Singer e transforma a escala em uma variável ordinal, o que pode enfraquecer as associações. Carreirão tampouco utiliza uma medida direta de sofisticação política e, ainda que seus resultados para a escolaridade sejam consistentes com tal perspectiva, o autor não os interpreta nesses termos.

Nas linhas que seguem, eu utilizo os mesmos dados de Singer para examinar de forma mais completa as limitações já apontadas por Reis e Carreirão. A Tabela 2 mostra os coeficientes dos efeitos da escolaridade e da sofisticação política sobre a probabilidade de resposta na escala direita-esquerda. A variável de sofisticação política consiste na codificação das respostas dadas às perguntas da pesquisa a respeito do significado dos termos direita e esquerda. Eu recodifico as respostas seguindo esquema similar ao de Fuks e Batista Pereira $(2011)^{6}$. Os coeficientes são baseados em modelos probit e estimam o efeito das variáveis independentes sobre a probabilidade de o(a) respondente se localizar na escala, tendo a categoria de não resposta como base de comparação. Uma expansão dessa análise em relação às análises de Carreirão (2002b) é que os modelos controlam por um conjunto de variáveis relevantes (que não são apresentadas para facilitar a visualização das estatísticas de interesse).

\footnotetext{
${ }^{6}$ A estratégia, utilizada para perguntas abertas de conhecimento, envolve a pós-codificação das respostas entre categorias de não resposta, respostas erradas, respostas parcialmente corretas e respostas corretas. Em contraste com Fuks e Batista Pereira (2011), utilizo aqui apenas a dimensão semântica das respostas, ignorando seu nível de abstração.
} 
Tabela 2

Efeito da escolaridade e da sofisticação política sobre a probabilidade de o(a) respondente se localizar na escala direita-esquerda, Brasil (1989, 1990)

\begin{tabular}{|l|c|c|c|}
\hline Estatística & $\mathbf{1 9 8 9}$ & $\mathbf{1 9 8 9}$ & $\mathbf{1 9 9 0}$ \\
\hline Coeficiente do efeito da escolaridade & $0,46 *$ & -0.04 & $0,72 *$ \\
\hline (Erro-padrão) & $(0,17)$ & $(0,18)$ & $(0,17)$ \\
\hline Mudança máxima de probabilidade & $0,13 *$ & -0.01 & $0,17 *$ \\
\hline Coeficiente do efeito da sofisticação & & $2,09 *$ & \\
\hline (Erro-padrão) & & $(0,19)$ & \\
\hline Mudança máxima de probabilidade & & $0,56 *$ & \\
\hline $\mathrm{n}$ & 2.048 & 2.043 & 2.217 \\
\hline
\end{tabular}

Fonte: Cultura Política I e III.

Modelos probit controlando por preferência partidária (variáveis indicadoras de PT, PMDB e PDS), escolaridade, conversas sobre política, leitura de jornais, religião (católica), renda, idade, sexo, região.

$*$ p. $<0,05$.

Os padrões na Tabela 2 são claros. A escolaridade aumenta a probabilidade de autolocalização na escala em 1989 e 19907. A diferença máxima de probabilidade, isto é, a diferença entre respondentes com o máximo e o mínimo de escolaridade na amostra é de 0,13 em 1989 e 0,17 em 1990. Obviamente, a escolaridade é apenas uma proxy para o conceito que realmente importa: a sofisticação política. A inclusão da variável no modelo para os dados de 1989 (onde está disponível) resulta em uma mudança máxima de 0,56 e faz o coeficiente da escolaridade virtualmente desaparecer. Há aqui, portanto, o problema clássico de viés de seleção que tem consequências importantes para o que se pode dizer a partir dos dados. Muito embora o viés de seleção com base na variável independente não seja um problema direto para a estimativa, o que se tem é um viés de seleção com base em uma variável condicional ou moderadora. Como mostram King et al. (1994, p. 139), se o efeito causal de $X$ (ideologia) sobre $Y$ (voto) varia entre observações e há viés de seleção com base na variável $Z$ que condiciona tal efeito (sofisticação), então a estimativa do efeito causal de $X$ poderá ser enviesada. Se o estudo em questão selecionar os valores de $Z$ (sofisticação) que aumentem o efeito de $X$ (ideologia), como é o caso nos estudos brasileiros sobre o voto ideológico, então o efeito de $X$ sobre $Y$ será sobrestimado (Ames e Smith, 2010, p. 16). Além disso, o viés de seleção com base na sofisticação pode também subestimar o efeito condicional da sofisticação política, visto que pode reduzir a variância das variáveis independentes em questão (Druckman e Kam, 2011).

A Tabela 3 apresenta outros dois testes que mostram como os resultados de Singer sobrestimam a relevância da autolocalização ideológica na explicação do voto. A tabela mostra os coeficientes de regressão probit multinomial do efeito da ideologia (de esquerda

\footnotetext{
7 Em todas as análises do artigo, as variáveis de controle, incluindo escolaridade e sofisticação política, estão recodificadas para variar entre 0 e 1 , de modo que os coeficientes indicam as mudanças máximas.
} 
para direita) sobre a probabilidade de voto em candidatos de direita em 1989 (estimativas dos candidatos de centro são omitidas por simplicidade) ${ }^{8}$. O Modelo 1 apenas replica as tabelas bivariadas de Singer utilizando a variável original de autolocalização (recodificada para variar entre 0 e 1). O Modelo 2 inclui variáveis de controle. O Modelo 3 inclui uma interação com a variável de escolaridade e o Modelo 4 mostra a interação com a variável de sofisticação política. Nos modelos com o termo interativo, os coeficientes-base para os efeitos da sofisticação política e da escolaridade são estimados, mas omitidos da tabela:

Tabela 3

Efeito da escala direita-esquerda sobre o voto para presidente (10 turno) por níveis de escolaridade e sofisticação política, Brasil (1989)

\begin{tabular}{|l|c|c|c|c|}
\hline Estatística & Modelo 1 & Modelo 2 & Modelo 3 & Modelo 4 \\
\hline Coeficiente da ideologia & $1,58^{*}$ & $1,03^{*}$ & -0.23 & 0,36 \\
\hline (Erro-padrão) & $(0,18)$ & $(0,20)$ & $(0,32)$ & $(0,33)$ \\
\hline Mudança máxima de probabilidade & $0,34^{*}$ & $0,16^{*}$ & -0.05 & 0,09 \\
\hline Ideologia*escolaridade & & & $4,52 *$ & \\
\hline (Erro-padrão) & & & $(0,92)$ & \\
\hline Mudança máxima de probabilidade & & & $0,46 *$ & \\
\hline Ideologia*sofisticação & & & & $2,03 *$ \\
\hline (Erro-padrão) & & & & $(0,78)$ \\
\hline Mudança máxima de probabilidade & & & & $0,26 *$ \\
\hline Controles & Não & Sim & Sim & Sim \\
\hline $\mathrm{n}$ & 1.353 & 1.306 & 1.306 & 1.306 \\
\hline
\end{tabular}

Fonte: Cultura Política I.

Modelos probit multinomiais (base: esquerda) controlando por confiança no presidente, preferência partidária (variáveis indicadoras de PT, PMDB e PDS), sofisticação política, escolaridade, interesse por política, conversas sobre política, leitura de jornais, religião (católica), renda, idade, sexo, residência urbana, emprego, região. $*$ p. $<0,05$.

O Modelo 1 confirma a alta (e espúria) associação estatística inicialmente mostrada por Singer, utilizando a escala original em vez da escala nominal. A diferença de probabilidade de voto à direita entre o eleitor mais à direita na escala e o mais à esquerda é de 0,34 . O resultado muda bastante quando se incluem as explicações alternativas. A inclusão de variáveis de controle no Modelo 2 faz a relação cair pela metade, com uma mudança máxima de 0,16 . Há aqui, portanto, o clássico problema do viés por omissão de variável de controle, uma vez que a associação encontrada por Singer cai pela metade quando se levam em consideração alguns fatores alternativos na explicação do voto. Mas

\footnotetext{
${ }^{8}$ A categoria de referência é o voto em um candidato de esquerda. Por simplicidade, os resultados utilizando os dados de 1990 são omitidos. Os padrões são os mesmos.
} 
ainda há o problema da heterogeneidade no efeito. Os Modelos 3 e 4 mostram que, quando se testa a diferença do efeito da ideologia entre respondentes mais e menos sofisticados(as) (medida seja pela escolaridade ou pela sofisticação), o coeficiente é nulo e não significativo entre respondentes menos sofisticados(as) (a maioria). Portanto, a reanálise dos dados traz más notícias para a perspectiva do voto ideológico. A associação estatística entre a autolocalização na escala direita-esquerda e o voto para presidente no Brasil é apenas observada em uma minoria de eleitores(as) mais sofisticados(as), que utilizam e entendem o significado da escala. O que se depreende da análise correta dos dados de Singer corresponde ao que a literatura criticada por ele já havia defendido.

\section{Estudo 2: A identidade ideológica do voto em Lula}

O artigo de Holzhacker e Balbachevsky (2007) oferece uma perspectiva mais matizada sobre o suposto voto ideológico para presidente. As autoras examinam os dados das pesquisas do Estudo Eleitoral Brasileiro (Eseb) de 2002 e 2006 para contrastar os efeitos da posição de classe e da ideologia sobre a escolha do candidato. O trabalho também é um dos primeiros a utilizar regressões multivariadas para analisar a decisão do voto em pesquisas de opinião no Brasil. As autoras defendem que diferenças nas distribuições de votos entre as conjunturas de 2002 e 2006 denotariam que a importância da ideologia (operacionalizada no artigo pela escala direita-esquerda) e da posição de classe sobre o voto seria condicional. As tabulações bivariadas e as análises de regressão do artigo mostram que a ideologia se associaria ao voto em 2002, mas não em 2006; enquanto a posição de classe se associaria ao voto em 2006, mas não em 2002.

No que se refere especificamente à associação entre ideologia e voto, a leitura apressada do texto pode levar à impressão de que, ao cabo, os problemas apontados pela literatura até então (e demonstrados na seção anterior) resultariam de fatores contextuais, uma vez que o voto ideológico teria se manifestado em 2002. No entanto, o exame mais detalhado revela que o artigo não resolve os problemas discutidos anteriormente e incorre em um conjunto adicional de equívocos na análise de dados.

O primeiro ponto problemático aparece na descrição das variáveis (Holzhacker e Balbachevsky, 2007, p. 298). De acordo com a descrição do modelo, a variável dependente seria o voto em Lula e a variável independente seria a ideologia, cuja variação seria de 0 (esquerda) a 10 (direita). Dessa forma, seria de esperar que um aumento na variável ideologia, isto é, a comparação de eleitores(as) da esquerda para a direita, diminuísse a probabilidade de voto em Lula. No entanto, a tabela de resultados (Holzhacker e Balbachevsky, 2007, p. 300) mostra que o coeficiente da ideologia é positivo em 2002 e 2006, e estatisticamente significativo em 2002, indicando que o aumento do valor da ideologia (de esquerda para direita) aumenta a probabilidade de voto em Lula. Os resultados são interpretados como evidência do voto ideológico, ainda que o sinal do coeficiente estimado seja oposto ao que se esperava. Obviamente, trata-se de um erro (de codificação 
ou formatação). Além disso, embora o coeficiente do efeito da ideologia em $2006(0,051)$ não seja estatisticamente significativo a $95 \%$ de confiança, ele não é estatisticamente distinto do efeito obtido em $2002(0,076)$, uma vez que os intervalos de confiança se justapõem. Portanto, não há base para afirmar que os dois efeitos sejam diferentes entre si. Outro problema é que o modelo de regressão utilizado é o de mínimos quadrados ordinários, próprio para variáveis dependentes contínuas. Sendo a variável dependente nominal e binária (voto em Lula), é possível que o modelo apresente estimativas enviesadas. Por fim, embora o estudo adicione variáveis de controle às análises, algo ausente em Singer, não há justificativas claras para a inclusão de variáveis como a satisfação com a democracia, além de omissões graves como a própria posição de classe. Além disso, a variável chamada "problema" é descrita como nominal - tipo de problema considerado mais importante pelos respondentes - (Holzhacker e Balbachevsky, 2007, p. 298), mas aparece no modelo como contínua, o que também pode gerar estimativas enviesadas.

Portanto, um conjunto de erros nas análises de regressão do artigo impede que se tome a evidência apresentada como válida sobre a importância da ideologia em qualquer um dos pleitos em questão. E cabe perguntar se uma análise adequada resgataria o voto ideológico ou apenas revelaria os mesmos problemas vistos nas análises de Singer. A Tabela 4 replica as análises de Holzhacker e Balbachevsky para 2002 (pleito no qual a ideologia teria supostamente sido relevante) e propõe as devidas correções para os problemas que geraram estimativas válidas. De maneira geral, a tabela mostra padrões muito similares à replicação das análises de Singer $^{9}$. A primeira coluna da tabela simplesmente indica a estimativa do efeito reportada por Holzhacker e Balbachevsky (2007, p. 300), que é (incorretamente) positiva e estatisticamente significativa. A segunda coluna mostra o modelo que corrige os problemas de codificação, remove as variáveis de controle para as quais não havia justificativa teórica e inclui novas variáveis de controle mais comuns na análise do voto no Brasil. Por fim, os dois últimos modelos apresentam as estimativas do modelo corrigido, incluindo interações com a escolaridade e a sofisticação política ${ }^{10,11}$.

\footnotetext{
9 Por ora, eu ignoro o problema da não resposta e suas consequências em 2002 e 2006 . Retornarei a esse ponto na seção seguinte do artigo.

10 A sofisticação política é medida aqui pelo somatório dos acertos nas quatro perguntas de conhecimento político incluídas nas pesquisas do Eseb de 2002 e 2006.

11 Todas as análises utilizando o Eseb a partir desse ponto do artigo levam em consideração os pesos pósestratificação da pesquisa.
} 
Tabela 4

Efeito da escala direita-esquerda sobre o voto para presidente ( $1^{\circ}$ turno) por níveis de escolaridade e sofisticação política, Brasil (2002)

\begin{tabular}{|l|c|c|c|c|}
\hline Estatística & $\begin{array}{c}\text { Modelo } \\
\text { original }\end{array}$ & $\begin{array}{c}\text { Modelo } \\
\text { corrigido }\end{array}$ & $\begin{array}{c}\text { Modelo } \\
\text { alternativo - } \\
\text { interação }\end{array}$ & $\begin{array}{c}\text { Modelo } \\
\text { alternativo - } \\
\text { interação }\end{array}$ \\
\hline Coeficiente da ideologia & $0,08^{*}$ & $-0.05^{*}$ & -0.01 & 0,00 \\
\hline (Erro-padrão) & $(0,03)$ & $(0,01)$ & $(0,02)$ & $(0,01)$ \\
\hline Mudança máxima de probabilidade & & $-0.16^{*}$ & -0.03 & 0,01 \\
\hline Ideologia*escolaridade & & & $-0.09 *$ & $(0,04)$ \\
\hline (Erro-padrão) & & & $-0.30 *$ & \\
\hline Mudança máxima de probabilidade & & & & $-0.11^{*}$ \\
\hline Ideologia*sofisticação & & & & $(0,03)$ \\
\hline (Erro-padrão) & & 1.306 & 1.306 & $-0.35^{*}$ \\
\hline Mudança máxima de probabilidade & & 1.353 & & 1.306 \\
\hline $\mathrm{n}$ & & & & \\
\hline
\end{tabular}

Fonte: Estudo Eleitoral Brasileiro (Eseb 2002).

Modelos corrigidos são probit controlando por avaliação do presidente, preferência partidária (variáveis indicadoras de PT, PMDB e PDS), sofisticação política, escolaridade, religião (católica), renda, idade, sexo, região.

Estatísticas baseadas em pesos pós-estratificação fornecidos pelo Eseb. $*$ p. $<0,05$.

O modelo corrigido mostra o coeficiente da ideologia na direção correta, isto é, quando se move na escala da esquerda para a direita, a probabilidade de voto em Lula diminui. No entanto, a associação é menor do que a reportada pelas autoras, tendo em vista que a mudança máxima de probabilidade é de 0,16 (próxima à de Singer para 1989). Os modelos com interação (colunas 3 e 4) reforçam o papel moderador da sofisticação política: a associação de ideologia e voto não é observada entre a maioria de eleitores(as) menos escolarizados(as) e sofisticados(as). Portanto, a sugestão de que o efeito da ideologia sobre o voto para presidente seria conjuntural não encontra base empírica nos dados utilizados. As condições estruturais que impediam a ocorrência do voto ideológico em massa observadas em 1989 não desapareceram em 2002 ou 2006.

\section{Estudo 3: Ideologia e sofisticação política}

A tentativa mais recente de resgate do voto ideológico aparece em Izumi (2019). O autor afirma que a falta de evidências em favor do voto de direita ou esquerda no Brasil se daria por problemas na medida de localização na escala direita-esquerda. A medida seria inadequada se usada sem as devidas correções para vieses de resposta. O argumento é o 
de que algumas pessoas que se localizam em um lado no espectro e votam em um(a) candidato(a) localizado(a) do outro lado o fazem não por não entenderem os termos, mas sim por terem uma compreensão peculiar da escala (Aldrich e McKelvey, 1977). Por exemplo, um(a) eleitor(a) de direita que vota em Lula pode ao cabo estar votando ideologicamente se considerar Lula como um candidato de direita. Se o(a) eleitor(a) de direita enxerga Lula à direita no espectro, mas não necessariamente à direita dos candidatos de direita, o que ocorre é que esse(a) eleitor(a) tem apenas um entendimento particular da escala, e podese dizer que vota ideologicamente. O modelo de mensuração usado por Izumi, então, aplica uma "correção" linear ao posicionamento do(a) eleitor(a), estimando a sua localização ideológica latente sem o viés de percepção da escala. A nova medida teria uma correlação mais alta com a decisão do voto para presidente, além de tal correlação ser independente do nível de sofisticação política do eleitorado, contrariando o consenso da literatura anterior.

O argumento de Izumi é sofisticado e certamente levanta uma questão relevante para o entendimento mais amplo sobre o uso de escalas de respostas numéricas em pesquisas de opinião, tema até então pouco explorado no Brasil. No entanto, para que qualquer eleitor(a) execute o cálculo de voto proposto pelo modelo espacial e, principalmente, para que a correção de mensuração proposta pelo autor faça sentido no caso brasileiro, é necessário que sejam preenchidos, por definição, três requisitos mínimos. Ele(a) deve: 1) conhecer os termos direita-esquerda e se localizar na escala; 2) localizar suas opções eleitorais (candidatos(as) e partidos) nessa mesma dimensão espacial; e 3) ordenar corretamente as opções eleitorais na dimensão espacial, localizando as opções de esquerda à esquerda das opções de direita (e vice-versa).

Os três requisitos descritos acima compõem a estrutura lógica do modelo espacial do voto, não sendo meros postulados cognitivos ad hoc. Sem que eleitores(as) se localizem e localizem os estímulos na dimensão direita-esquerda, não há espaço por definição e, por conseguinte, não há decisão do voto baseada no modelo espacial. Tampouco se pode chamar de ideológico(a) um(a) eleitor(a) que inverte o significado dos termos direita e esquerda. Apenas se pode dizer que um eleitorado vota com base na clivagem direita-esquerda na medida em que se preencham esses três requisitos. Além disso, uma vez que tais requisitos denotam tarefas cognitivas, a sofisticação política seria, em tese, um condicionante importante do voto ideológico.

Com base nos mesmos dados das ondas de 2002 a 2014 do Eseb, a Tabela 5 apresenta o percentual de respondentes em cada pesquisa que preenche cada um dos três requisitos do modelo espacial do voto ${ }^{12}$. Parte considerável do eleitorado brasileiro sequer se identifica na dimensão espacial direita-esquerda (requisito 1). Em 2002, o percentual de

\footnotetext{
12 Para os dois primeiros requisitos, considero as respostas "não conhece os termos direita e esquerda", "não sabe" e "não respondeu" como recusas em utilizar o espaço direita-esquerda. Ainda que possam ter causas e significados distintos, tais respostas têm o mesmo efeito prático: o de impedir a ocorrência do voto ideológico.
} 
respostas válidas é o mais alto, atingindo $77 \%$, enquanto não passa de $56 \%$ em $2014^{13}$. Cabe mencionar que esses percentuais de resposta são mais baixos do que os da maioria das perguntas atitudinais do Eseb e baixos quando comparados aos de outras democracias da região (Zechmeister, 2015). No que se refere a localizar os estímulos (partidos e candidatos) no espaço (requisito 2 ), os percentuais caem ainda mais, variando entre $61 \%$ em 2002 e $44 \%$ em 201414. No que se refere ao ordenamento correto dos estímulos (requisito 3), a tabela mostra resultados ainda mais problemáticos ${ }^{15}$. Em 2002, o percentual de eleitores(as) que preenchem o requisito 3 é de $56 \%$, e não passa de $40 \%$ nas três eleições posteriores, atingindo $29 \%$ em 2014 . Além do mais, o modelo do voto espacial requer - por definição - que os três requisitos sejam preenchidos conjuntamente. A última linha da tabela mostra que o percentual de eleitores(as) que poderiam votar com base no espaço direitaesquerda nunca passa de 41\% (2002). Em 2014, apenas cerca de 20\% do eleitorado preenche os três requisitos para o voto ideológico.

\section{Tabela 5}

\section{Frequência do eleitorado que preenche os requisitos cognitivos para voto ideológico no Brasil (2002-2014) (\%)}

\begin{tabular}{|l|c|c|c|c|}
\hline Requisito & $\mathbf{2 0 0 2}$ & $\mathbf{2 0 0 6}$ & $\mathbf{2 0 1 0}$ & $\mathbf{2 0 1 4}$ \\
\hline 1. O eleitor se localiza no espaço esquerda-direita. & 76,81 & 58,17 & 60,57 & 55,95 \\
\hline $\begin{array}{l}\text { 2. O eleitor localiza os estímulos (partidos e candidatos) no espaço } \\
\text { esquerda-direita. }\end{array}$ & 60,99 & 51,36 & 51,64 & 43,9 \\
\hline $\begin{array}{l}\text { 3. O eleitor ordena corretamente os estímulos (partidos e candidatos) } \\
\text { no espaço direita-esquerda. }\end{array}$ & 55,78 & 36,08 & 40,09 & 28,59 \\
\hline Preenche os requisitos 1, 2 e 3. & 40,66 & 25,65 & 28,01 & 19,57 \\
\hline
\end{tabular}

Fonte: Estudo Eleitoral Brasileiro (Eseb 2002, 2006, 2010, 2014).

Estatísticas baseadas em pesos pós-estratificação fornecidos pelo Eseb.

A literatura anterior já havia discutido as implicações substantivas dos problemas descritos acima (Reis, 2000a; Carreirão, 2002a, 2002b). Ainda que se observe uma associação estatística entre ideologia e voto, ela reflete uma relação que descreveria o comportamento de poucos(as). O modelo de mensuração proposto por Izumi nada faz para resolver essa questão. Embora o artigo não ignore completamente a possibilidade de que eleitores(as) ordenem incorretamente as opções eleitorais no espaço direita-esquerda

\footnotetext{
13 Tampouco se podem atribuir as baixas taxas de resposta à dificuldade dos(as) respondentes em utilizar a escala de resposta numérica utilizada. As perguntas sobre quanto os(as) respondentes gostam de partidos e políticos(as) específicos utilizam a mesma escala e apresentam taxas de resposta significativamente mais altas. ${ }_{14}$ Seguindo o modelo de Izumi, são consideradas aqui as respostas sobre PT, PSDB, PMDB, os candidatos de PT e PSDB, e o terceiro colocado na disputa de cada eleição. Em 2014, apenas as perguntas sobre os partidos foram feitas.

15 Entre os(as) eleitores(as) que não preenchem o requisito 3, a Tabela 5 também inclui aqueles(as) que localizam PSDB e PT no mesmo ponto do espaço direita-esquerda. Não se pode falar em modelo espacial do voto, por definição, se o(a) eleitor(a) não estabelece distinção espacial entre as duas opções.
} 
(requisito 3), o autor rechaça o problema alegando que, "(...) mesmo que o eleitor não saiba exatamente qual é a localização deles na escala ideológica, ele provavelmente irá posicionálos na ordem correta" (Izumi, 2019, p. 34). No entanto, como mostra a Tabela 5, em três das quatro eleições analisadas, menos de um terço do eleitorado é capaz de ordenar corretamente os partidos e candidatos no espaço direita-esquerda.

Por que grande parte do eleitorado não preenche os requisitos do voto ideológico? O voto espacial com base em conceitos políticos abstratos como "direita" e "esquerda" demanda um nível de envolvimento cognitivo que a maior parte do eleitorado brasileiro, devido a questões estruturais, não apresenta. Trata-se da teoria da interação da sofisticação política (Sniderman, Brody e Tetlock, 1991; Batista Pereira, 2013; Batista Pereira, Fuks e Casalecchi, 2014). Segundo essa perspectiva, o efeito causal (ou a mera associação estatística) de uma opinião política sobre um comportamento (ou mesmo sobre outra opinião) depende da sofisticação política dos eleitores. Cidadãos(ãs) mais sofisticados(as) tendem a reconhecer os diferentes estímulos políticos e ser afetados por eles. Sendo assim, a sofisticação política não importa apenas como um moderador estatístico do voto ideológico (em um termo interativo ou multiplicativo no modelo de regressão), mas também determina a probabilidade de um(a) respondente reconhecer e utilizar o espaço direita-esquerda em primeiro lugar. A Tabela 6 mostra o efeito da sofisticação política e da escolaridade sobre a probabilidade de $o(a)$ respondente preencher os três requisitos do modelo espacial. As estimativas se baseiam em modelos probit que controlam por variáveis relevantes ${ }^{16}$.

\section{Tabela 6 \\ Efeito da sofisticação política e escolaridade sobre a probabilidade de o(a) respondente preencher os três requisitos cognitivos do voto ideológico, Brasil (2002-2014)}

\begin{tabular}{|l|c|c|c|c|}
\hline Estatística & $\mathbf{2 0 0 2}$ & $\mathbf{2 0 0 6}$ & $\mathbf{2 0 1 0}$ & $\mathbf{2 0 1 4}$ \\
\hline Coeficiente do efeito da sofisticação & $1,05^{*}$ & $1,23 *$ & $0,93 *$ & $0,82^{*}$ \\
\hline (Erro-padrão) & $(0,11)$ & $(0,22)$ & $(0,32)$ & $(0,13)$ \\
\hline Mudança máxima de probabilidade & $0,34 *$ & $0,35 *$ & $0,28 *$ & $0,21 *$ \\
\hline Coeficiente do efeito da escolaridade & $1,11^{*}$ & 0,22 & $1,53 *$ & $0,78 *$ \\
\hline (Erro-padrão) & $(0,14)$ & $(0,22)$ & $(0,30)$ & $(0,14)$ \\
\hline Mudança máxima de probabilidade & $0,36 *$ & 0,06 & $0,46 *$ & $0,20 *$ \\
\hline $\mathrm{n}$ & 2444 & 1000 & 1833 & 3050 \\
\hline
\end{tabular}

Fonte: Estudo Eleitoral Brasileiro (Eseb 2002, 2006, 2010, 2014).

Modelos probit controlando por escolaridade, status socioeconômico, idade, sexo, região.

Estatísticas baseadas em pesos pós-estratificação fornecidos pelo Eseb.

$*$ p. $<0,05$.

\footnotetext{
${ }^{16}$ A medida de sofisticação usada aqui apenas utiliza o somatório das quatro perguntas de conhecimento político de cada ano. Izumi inclui itens em sua medida que nada têm a ver com o conceito de sofisticação, como a filiação a sindicatos, por exemplo. Para uma discussão da mensuração do conceito, ver Batista Pereira (2013) e Batista Pereira, Fuks e Casalecchi (2014).
} 
Os resultados na Tabela 6 mostram o efeito positivo ubíquo da sofisticação política sobre a probabilidade de preenchimento dos requisitos cognitivos do voto ideológico. Em 2002 e 2006, a comparação entre um(a) respondente que acerta as quatro perguntas de conhecimento do Eseb e um(a) que erra as quatro indica que o(a) primeiro(a) tem 0,35 a mais de probabilidade de preencher os três requisitos. Em 2014, esse efeito é menor $(0,21)$, mas, mesmo assim, substantivamente alto. Em comparação com as variáveis de controle do modelo (omitidas por simplicidade), a sofisticação tem os efeitos mais altos. A escolaridade também tem associação positiva, que apenas não é alta e estatisticamente significativa em 2006.

Enquanto os requisitos 1 e 2 produzem altas taxas de não resposta e estimativas enviesadas devido ao viés de seleção, as consequências do não preenchimento do requisito 3 (ordenamento correto) são problemáticas porque resultam em respostas que simplesmente não fazem sentido. Ao ignorar o fato de que grande parte dos(as) eleitores(as) não preenchem o requisito 3 , as análises de Izumi misturam eleitores para os quais o modelo espacial do voto se aplica (assim como o escalonamento A-M) com outros para os quais o modelo não faz sentido lógico. Como a proporção de eleitores(as) que não preenchem o requisito é alta e menos sofisticada politicamente, o modelo A-M empresta coerência dos mais aos menos sofisticados ao "fixar" as localizações de PSDB e PT no ordenamento correto. $\mathrm{O}$ artigo explica que o modelo A-M é estatisticamente identificado porque impõe a localização ordenada de forma correta a dois estímulos (Izumi, 2019, p. 35). O modelo aplica essa correção às posições de PSDB e PT, o que significa que, independentemente da resposta dada na escala da pergunta, assume-se que todos(as) os(as) respondentes "localizam" o PSDB a 0,25 e o PT a -0,25 na nova escala, isto é, localizam o PSDB à direita do PT na escala. Ora, se, conforme mostram as Tabelas 5 e 6, uma enorme parcela menos sofisticada não ordena corretamente os estímulos no espaço direita-esquerda (requisito 3), as correções impostas pelo modelo simplesmente "transformam" tais respondentes de modo a ordenar artificialmente seu uso equivocado da escala direita-esquerda. Sendo assim, não é surpresa que, ao cabo, os resultados encontrados mostrem que eleitores(as) de direita votem predominantemente nos(as) candidatos(as) de direita, enquanto eleitores(as) de esquerda votem predominantemente nos(as) candidatos(as) de esquerda. Mais ainda, não é surpresa que, uma vez que o modelo corrige artificialmente os erros de ordenamento dos(as) respondentes menos sofisticados(as), a sofisticação deixe de apresentar o papel moderador nas análises. Isso ocorre porque as "correções" impostas automaticamente produzem esse padrão, o que leva o autor a apresentar resultados artificiais e, consequentemente, inválidos.

Para corroborar empiricamente o diagnóstico oferecido acima, a Tabela 7 apresenta os modelos probit de decisão do voto para o candidato à direita nos quais a principal variável independente é a autolocalização ideológica. Eu incluo variáveis de controle relevantes para a análise do voto no Brasil, que são listadas na tabela mas cujos coeficientes são omitidos por simplicidade. Além disso, os modelos incluem um termo interativo entre a ideologia e uma variável indicando se o(a) respondente preenche ou não os três requisitos do voto 
ideológico (o coeficiente base de tal variável também é omitido da tabela). Se a suspeita levantada no parágrafo anterior estivesse correta, o coeficiente da ideologia entre os(as) respondentes que não preenchem os requisitos seria nulo ou até negativo, enquanto o termo interativo seria positivo, indicando que o efeito da ideologia é observado apenas entre aqueles(as) que preenchem os requisitos.

Tabela 7

Efeito da escala direita-esquerda moderado pelos requisitos cognitivos do voto espacial, Brasil (2002-2014)

\begin{tabular}{|l|c|c|c|c|}
\hline Estatística & $\mathbf{2 0 0 2}$ & $\mathbf{2 0 0 6}$ & $\mathbf{2 0 1 0}$ & $\mathbf{2 0 1 4}$ \\
\hline Ideologia & 0,03 & -0.02 & -0.07 & -0.03 \\
\hline (Erro-padrão) & $(0,02)$ & $(0,04)$ & $(0,04)$ & $(0,02)$ \\
\hline Mudança máxima de probabilidade & 0,08 & -0.03 & -0.17 & -0.08 \\
\hline Ideologia*requisitos & $0,09 *$ & $0,18^{*}$ & $0,37^{*}$ & $0,21^{*}$ \\
\hline (Erro-padrão) & $(0,03)$ & $(0,06)$ & $(0,06)$ & $(0,04)$ \\
\hline Mudança máxima de probabilidade & $0,31^{*}$ & $0,34^{*}$ & $0,68 *$ & $0,42^{*}$ \\
\hline $\mathrm{n}$ & 1,450 & 470 & 884 & 1442 \\
\hline
\end{tabular}

Fonte: Estudo Eleitoral Brasileiro (Eseb 2002, 2006, 2010, 2014).

Modelos probit controlando por avaliação de governo, preferência partidária (PT e PSDB), escolaridade, renda, idade, sexo, região, avaliação da economia (2010-2014) e Bolsa Família (2010-2014).

$*$ p. $<0,05$.

Estatísticas baseadas em pesos pós-estratificação fornecidos pelo Eseb.

Em conjunto, os resultados das Tabelas 5, 6 e 7 são problemáticos para a defesa do voto ideológico. A Tabela 7 mostra que a autolocalização na escala direita-esquerda está associada apenas ao voto para presidente entre eleitores(as) que preenchem os requisitos cognitivos do voto ideológico. A associação chega a ser negativa (mas não estatisticamente significativa) entre respondentes que não preenchem os requisitos em três das quatro pesquisas analisadas. Ao imputar o ordenamento correto em seu modelo para os(as) eleitores(as) menos sofisticados(as), Izumi extrapola resultados válidos entre uma minoria para um grupo mais amplo de respondentes. Ao fazer isso, a imputação também neutraliza o efeito condicional da sofisticação, uma vez que o modelo empresta os requisitos (especialmente o terceiro) a respondentes que não os preenchem. Sendo assim, os resultados apenas confirmam a validade das premissas fundamentais do modelo espacial, que não podem ser ignoradas. Como apenas uma minoria (Tabela 5) de eleitores(as) mais sofisticados(as) (Tabela 6) preenche tais requisitos, o que se pode concluir é que a associação estatística entre autolocalização na escala direita-esquerda e voto, tão celebrada por parte da literatura, é observada apenas para uma minoria de eleitores(as), algo que a literatura do campo oposto já conhecia. 


\section{Correlação e causalidade}

A literatura em favor da existência do voto ideológico vai além de afirmar a associação estatística entre a escala direita-esquerda e o voto. Singer (1999) ocupa boa parte das primeiras páginas de seu livro comparando os estudos eleitorais à meteorologia. Para ele, cientistas políticos que ignoram a clivagem direita-esquerda seriam como meteorologistas incompetentes por não serem capazes de prever adequadamente os resultados das eleições. Izumi fala explicitamente sobre a "importância preditiva" da variável ideologia (2019, p. 53). Nas linhas abaixo, proponho um exercício adicional de ceticismo. Mesmo a associação estatística mais alta entre ideologia e voto observada (apenas) entre o eleitorado mais sofisticado não indica uma relação de causa e efeito.

Quando duas opiniões ou preferências parecem estar correlacionadas, cabe perguntar qual delas é a causa e qual é o efeito. Alguns estudos do comportamento eleitoral no Brasil anteriores a Singer, Holzhacker e Balbachevsky e Izumi já haviam feito essa pergunta. O trabalho de Reis (1988), o quarto capítulo da tese de Castro (1994) e o artigo de Reis e Castro (1992), por exemplo, discutem e examinam exaustivamente (mesmo com dados transversais) a possiblidade de que eleitores(as) formem suas preferências por candidatos(as) e partidos antes de outras preferências políticas (como aquela entre direita e esquerda), o que denotaria o sentido reverso na relação de causalidade entre opinião e voto. O trabalho mais recente de Pimentel, Russo e Avelino (2019) também mostra, por meio de um experimento de survey, que eleitores(as) tendem a ajustar suas posições na escala direita-esquerda quando informados sobre a ideologia dos candidatos. A literatura da psicologia política fornece os fundamentos conceituais e teóricos que explicam esse padrão: a causa é aquela atitude mais forte e efetiva. Atitudes efetivas são estáveis ao longo do tempo, afetam o processamento de informações e produzem consequências no comportamento dos indivíduos (Krosnick e Rahn, 1994, p. 279). Logicamente, uma opinião que muda frequentemente ao longo do tempo não pode gerar uma opinião que permanece constante durante o mesmo período. Sendo assim, um requisito mínimo para que a ideologia exerça uma influência causal sobre o voto é que ela seja mais estável ao longo do tempo. No entanto, ainda que a literatura utilize linguagem causal para se referir à associação estatística entre ideologia e voto, o uso de dados transversais (coletados em um único ponto do tempo) limita o alcance da afirmação. De todos os estudos sobre o tema no Brasil, o único que se vale de dados de painel é o de Ames, García-Sánchez e Smith (2012), o qual não encontra um efeito da escala direita-esquerda sobre o voto entre 2002 e 2006.

Nas linhas que seguem, eu utilizo o Estudo de Painel Eleitoral Brasileiro (Beps, na sigla em inglês) de 2010 (Ames et al., 2013) para investigar se, sob o ponto de vista da estabilidade das atitudes, a ideologia pode ser considerada uma causa do voto para presidente entre os(as) poucos(as) respondentes para os(as) quais a associação estatística é válida. O Beps é uma pesquisa de opinião coletada em painel (ao longo do tempo) de 
alcance nacional, composta de três ondas de coleta ${ }^{17}$. Nas análises abaixo, utilizo as ondas de setembro (anterior ao início do Horário Gratuito de Propaganda Eleitoral - HGPE) e outubro (após o pleito).

A primeira pista que levanta dúvidas sobre o efeito causal da ideologia aparece no teste mais simples similar ao que foi proposto por Converse (1964). Se opiniões mais fortes e com efeito causal sobre comportamentos e escolhas são mais estáveis ao longo do tempo, então a correlação entre as respostas na escala direita-esquerda dadas em setembro e outubro deveria ter pelo menos a mesma magnitude que as correlações na preferência pelos(as) candidatos(as). Não é esse o caso. Enquanto a correlação bivariada para a ideologia é de 0,25 (estatisticamente significativa a 0,05) para toda a amostra, a correlação para o voto ou não em Dilma é de 0,49 (estatisticamente significativa a 0,05) e de 0,48 (estatisticamente significativa a 0,05 ) para o voto ou não em Serra. Os padrões são semelhantes quando se consideram apenas os(as) respondentes que preenchem os critérios do voto ideológico discutidos na Tabela 5. Ademais, a correlação entre as respostas à pergunta sobre ideologia entre setembro e outubro é mais alta precisamente entre os eleitores mais sofisticados, tal como já encontrado por Ames e Smith (2010, p. 21) e Batista Pereira $(2014)^{18}$.

A segunda pista sobre a direção de causalidade na relação entre ideologia e voto pode ser encontrada por meio da estratégia proposta de forma teórica por Granger (1969) e utilizada por Lenz (2009) para analisar o voto nos Estados Unidos. A estratégia é conhecida como teste de causalidade de Granger, ou modelos de regressão com defasagem. Trata-se de duas regressões separadas, mas examinadas conjuntamente. Na primeira, utiliza-se o voto em outubro como variável dependente e incluem-se o voto e a ideologia em setembro (antes do HGPE) como variáveis independentes principais. Na segunda regressão, utilizamse as mesmas variáveis independentes, mas substitui-se o voto pela ideologia em outubro como variável dependente. A comparação entre os modelos serve para observar qual das duas variáveis do corte transversal em outubro (voto ou ideologia) é mais estável ao longo do tempo, isto é, correlacionada consigo mesma em setembro, enquanto se controla estatisticamente pelo valor da outra em setembro. A análise da Tabela 8 reporta os resultados apenas entre respondentes da pesquisa em outubro que preenchem os três requisitos do voto ideológico discutidos na seção anterior (Tabela 5): localizam-se na escala direita-esquerda, localizam partidos e candidatos(as) e ordenam corretamente os(as) candidatos(as) na escala direita-esquerda ${ }^{19}$.

17 Os dados do Beps de 2010 estão disponíveis na página do Banco Interamericano de Desenvolvimento. Disponível em: <https://publications.iadb.org/en/publication/12807/brazilian-electoral-panel-studies-beps>. Acesso em: 4 jun. 2019.

${ }^{18}$ A medida de sofisticação do Beps consiste em três perguntas de conhecimento político sobre: o nome do presidente dos Estados Unidos, o número de estados brasileiros e a duração do mandato do presidente do Brasil.

19 O modelo com o voto de variável dependente é do tipo probit, uma vez que a variável só considera (por simplificação) os votos de Dilma e Serra. O modelo com a ideologia como variável dependente é do tipo probit 
Tabela 8

Teste de causalidade de Granger do voto ideológico, Brasil (2010)

\begin{tabular}{|l|c|c|}
\hline & Voto em outubro & Ideologia em outubro \\
\hline Ideologia antes do HGPE & 0,17 & $1,03^{*}$ \\
\hline (Desvio-padrão) & $(0,62)$ & $(0,49)$ \\
\hline Voto antes do HGPE & $1,40^{*}$ & $0,64^{*}$ \\
\hline (Desvio-padrão) & $(0,37)$ & $(0,21)$ \\
\hline $\mathrm{n}$ & 106 & 121 \\
\hline Pseudo $\mathrm{R}^{2}$ & 0,41 & 0,08 \\
\hline
\end{tabular}

Fonte: Brazilian Electoral Panel Study 2010 (Ames et al., 2013).

Modelos probit para o voto e probit ordinal para ideologia, controlando pela avaliação do presidente, preferência partidária (variáveis indicadoras de PT), sofisticação política, escolaridade, religião (católica e protestante), renda, sexo e região.

$*$ p. $<0,05$.

Estatísticas baseadas em pesos pós-estratificação fornecidos pelo Beps.

Tomados em conjunto, os resultados dos dois modelos não sustentam a hipótese de que a ideologia de fato preceda o voto mesmo entre os(as) poucos(as) eleitores(as) que preenchem os critérios cognitivos e lógicos para o voto ideológico ${ }^{20}$. O modelo do voto em outubro mostra que a escolha do(a) candidato(a) está associada ao voto antes do HGPE, mas não à ideologia no mesmo período. O modelo da ideologia em outubro mostra que essa escolha está associada tanto à ideologia quanto ao voto antes do HGPE, mas que tal associação é de magnitude maior para a primeira. Sendo assim, o teste de causalidade de Granger apenas confirma o exame mais simples da estabilidade temporal das preferências políticas. Entre os eleitores(as) que preenchem os requisitos para o voto ideológico, a ideologia não é uma preferência suficientemente estável para ser considerada uma causa do voto ${ }^{21}$.

Uma estratégia mais direta para testar a direção causal entre ideologia e voto utilizando dados de painel é o uso de análise de trajetória (ou modelos de equações estruturais). Enquanto os modelos de Granger acima consideram os efeitos das variáveis em setembro sobre a ideologia e o voto em outubro, a análise de trajetória permite fazê-lo ao mesmo tempo que se testa diretamente a direção de causalidade entre as duas variáveis em

ordinal, uma vez que a variável é ordinal. As análises também levam em conta os pesos pós-estratificação da amostra.

20 O número de observações dos modelos é baixo porque as análises incluem apenas respondentes que preenchem os três critérios do voto ideológico na onda 3 (e o critério 1 nas duas ondas), além de se restringir apenas a eleitores de Dilma e Serra. As análises produzem os mesmos resultados quando se considera a totalidade $\operatorname{dos}($ as) respondentes que apenas se localizam na escala direita-esquerda (critério 1), mas não necessariamente localizam ou ordenam corretamente as opções (critérios 2 e 3 ).

21 Como base de comparação, quando o mesmo tipo de análise é feito para a avaliação da economia, os resultados indicam que essa atitude de fato tem precedência temporal sobre o voto. Sendo assim, os resultados negativos para a ideologia não se devem ao tipo de teste, uma vez que outra varável apresenta resultados positivos. 
outubro. O modelo apresentado aqui é similar ao de Howell (1986). Os quadrados do diagrama da Figura 1 representam as variáveis de ideologia e voto em setembro e outubro. As trajetórias especificadas são coeficientes de regressão. Em linhas gerais, a estrutura do modelo especifica efeitos mútuos entre ideologia e voto em outubro, ao mesmo tempo que leva em conta a estabilidade de cada variável ao longo do tempo (efeito da variável medida em setembro sobre ela mesma em outubro). Sendo assim, o modelo leva em conta a estabilidade temporal das duas variáveis para investigar, caso exista associação estatística entre elas em outubro, qual exerce efeito causal sobre a outra. Os modelos controlam por variáveis relevantes e apenas incluem respondentes que preenchem os requisitos do voto ideológico $(n=104)$.

Figura 1

Modelo de análise de trajetória não recursivo entre ideologia e voto ao longo do tempo

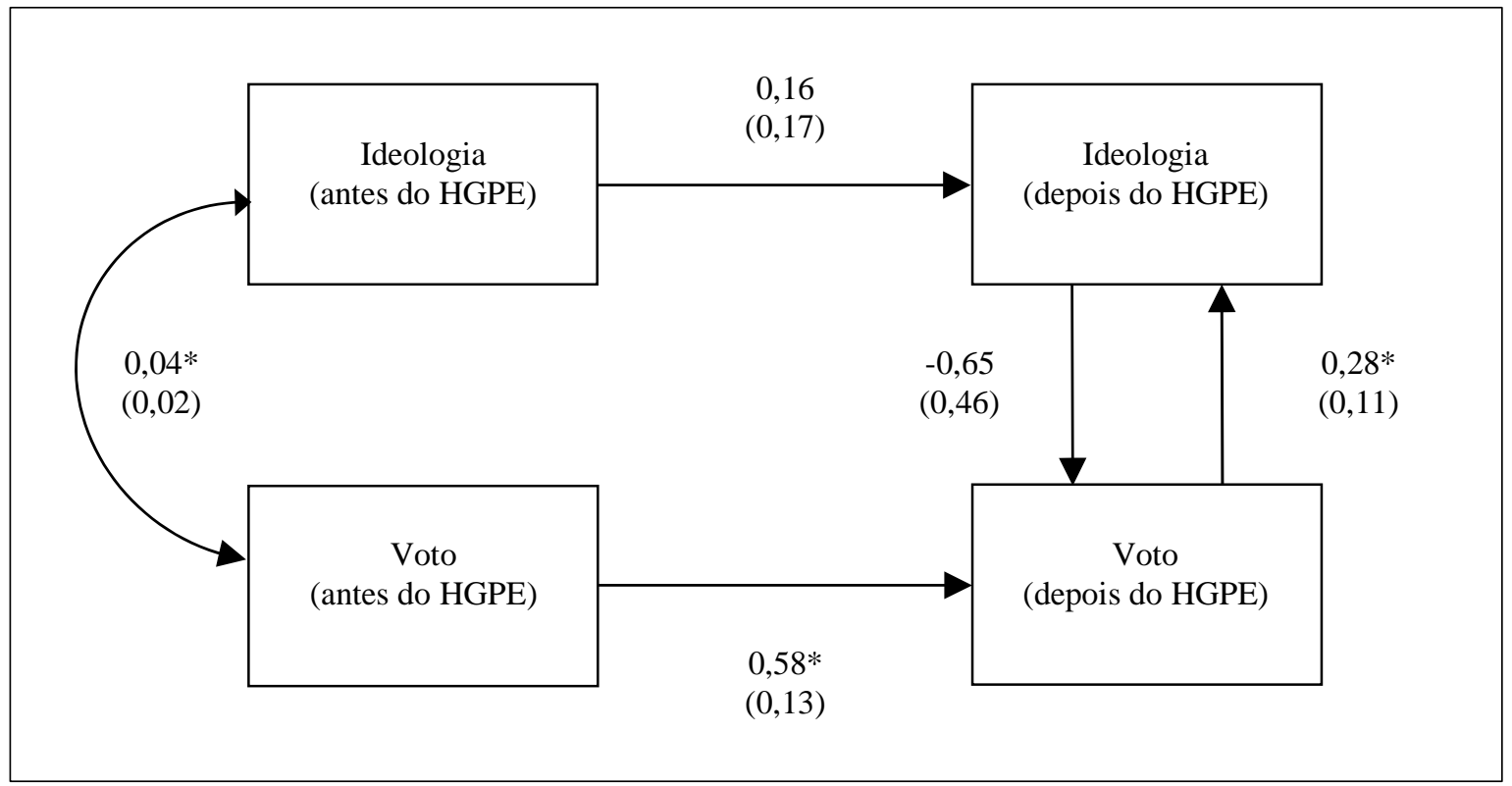

Fonte: Brazilian Electoral Panel Study 2010 (Ames et al., 2013).

Modelos com estimativa por máxima verossimilhança e erros robustos, controlando pela avaliação do presidente, preferência partidária (indicadoras de PT), sofisticação política, escolaridade, religião (católica e protestante), renda, sexo e região.

$*$ p. $<0,05$.

Os resultados reportados na Figura 1 confirmam as suspeitas levantadas pelas estratégias de modelagem anteriores. Quando se estimam efeitos simultâneos entre ideologia e voto em outubro ao mesmo tempo que se considera a estabilidade de tais preferências ao longo do tempo, é o voto que exerce efeito sobre a ideologia $(0,28$, estatisticamente significativo), e não o contrário (-0,65, não significativo). Como já se sabia, a preferência pelo candidato é mais estável no tempo (coeficiente estatisticamente 
significativo de 0,58$)$, enquanto a ideologia não apresenta o mesmo padrão $(0,16$, não significativo). Portanto, a análise de trajetória mostra que mesmo os(as) poucos(as) eleitores(as) mais sofisticados(as) para os(as) quais se observa uma associação estatística entre ideologia e voto tendem a ajustar seu posicionamento na escala direita-esquerda em função do(a) candidato(a) que preferem.

\section{Considerações finais}

Reitere-se: não há evidência de que a clivagem direita-esquerda exerça efeito causal sobre o voto para presidente no eleitorado brasileiro. Diante da análise cuidadosa dos mesmos dados de opinião pública usados pela literatura anterior, os resultados mostrados aqui sugerem que tal relação poderia apenas ser observada, no melhor dos casos, em uma minoria de eleitores(a) politicamente sofisticados(as). Porém, a análise de dados de painel mostra que, mesmo entre estes(as), não há evidências claras de que a associação estatística observada entre ideologia e voto represente uma relação causal. Sendo assim, a replicação e a reanálise dos dados sugerem que não há bases empíricas para contestar a conclusão predominante na literatura sobre o voto no Brasil. Entre os aspectos que explicariam os limites da clivagem direita-esquerda na explicação do voto no país, estariam o fato de a democracia brasileira ser relativamente recente (Reis e Castro, 1992; Ames e Smith, 2010), o que dificultaria o processo de socialização e transmissão de ideais e valores democráticos entre os(as) eleitores(as). Além disso, o ambiente institucional altamente complexo e pouco programático do país seria outro obstáculo (Rennó, 2004; Zechmeister, 2015). Eleitores(as) também teriam dificuldades em compreender os termos abstratos e suas implicações concretas devido às altas taxas de pobreza e desigualdade social entre eles(as), além de um sistema educacional ineficiente (Schlegel, 2010). Nesse sentido, o grande impedimento para que o eleitorado brasileiro vote de forma ideológica (com base nos termos direita-esquerda) não se encontra em supostas deficiências dos dados ou métodos de pesquisa utilizados e, menos ainda, em supostas disposições antidemocráticas dos(as) estudiosos(as) do fenômeno eleitoral. Há barreiras estruturais que precisam ser compreendidas e removidas para que o chamado voto ideológico passe a guiar os resultados eleitorais no Brasil.

Com base nos problemas metodológicos apontados na literatura que afirma a relevância da clivagem direita-esquerda do voto no Brasil, é possível extrair um conjunto de critérios empíricos que devem ser atendidos por estudos futuros que tenham o mesmo objetivo teórico. Com efeito, tais critérios valeriam para quaisquer trabalhos visando a mostrar que algum fator "determinante" do comportamento eleitoral no Brasil tenha papel maior do que o consenso existente sugere. O primeiro critério é que a taxa de não resposta em perguntas de pesquisas de opinião seja baixa. Para que uma atitude ou preferência seja considerada forte, um indicador inicial de tal atributo é a frequência de respostas em perguntas de opinião nas quais as pessoas manifestam tal preferência (Krosnick e Milburn, 1990). Além disso, a manifestação de preferências fortes e cristalizadas também tende a ser 
menos afetada pelo formato das perguntas (Lavine et al., 1998). Não é esse o caso da escala direita-esquerda em pesquisas de opinião no Brasil, que apresenta taxas de resposta mais baixas se comparadas a perguntas sobre outros assuntos. O segundo critério é que a não resposta não esteja associada a indicadores de que a atitude simplesmente não exista no repertório para parte do eleitorado. Embora respondentes muitas vezes não manifestem publicamente certas atitudes em virtude do impacto social de suas opiniões (como preconceitos, por exemplo), não é esse o caso para a escala direita-esquerda, cuja baixa taxa de resposta tem como principal correlato a sofisticação política, o que indica que não há cognições que sustentem uma opinião minimamente embasada (Krosnick e Milburn, 1990). O terceiro critério é que a correlação entre a preferência em questão e suas supostas consequências não seja condicionada por indicadores da força de tal atitude, principalmente se tais indicadores mostrarem que essa atitude, ainda que manifesta, é fraca para a maioria do eleitorado. Nesse sentido, ainda que muitos(as) respondentes se posicionem na escala direita-esquerda e esta esteja correlacionada com o voto, é preciso mostrar que tal correlação é válida independentemente de indicadores da força de tal atitude (como a sofisticação). Do contrário, a aparente correlação leva pesquisadores a celebrar um numerador com base em um falso denominador, para adaptar um jogo de palavras caro a Luskin (2002, p. 291). Por fim, o quarto critério é que, ainda que a correlação seja alta, é preciso demonstrar que a suposta causa constitui uma preferência mais estável do que a preferência tomada como efeito. Qualquer estudo que pretenda trazer a "boa nova" precisa enfrentar tais critérios de forma direta e conclusiva.

Seja como for, parecem ser duas as motivações principais da corrente que nega os matizes sociais e sociopsicológicos do processo eleitoral brasileiro. A primeira é de natureza normativa. Como argumentam Kuklinski e Quirk (2000, p. 154), um debate sobre competência cívica permeia os estudos do comportamento político, e neste "a noção de um eleitorado competente é normativamente atraente". Nesse sentido, alguns(mas) estudiosos(as) da democracia brasileira desejam "revelar" a competência cívica do eleitorado de modo a evitar rótulos de elitismo antidemocrático. Tal postura redunda, de forma análoga e igualmente absurda, na sugestão de que seria racista um(a) estudioso(a) que examina e expõe os efeitos da desigualdade racial na sociedade brasileira. Pelo contrário, o reconhecimento do problema da desigualdade e de seus efeitos sobre o eleitorado promove o esforço da disciplina para que se entendam de forma realista as condições estruturais que impedem ou fomentam a participação política competente. A segunda motivação da postura que nega os matizes sociais e sociopsicológicos do processo eleitoral brasileiro parece ser epistemológica. A ideia de que eleitores(as) se orientam em um espaço unidimensional entre direita e esquerda ao votarem, sem que fatores de natureza social e cultural importem, dá sustentação à filosofia que apregoa a "autonomia do institucional". Em outras palavras, provar que o sistema heurístico simples e elegante do(a) eleitor(a) mediano(a) proposto por Downs (1957) - e tomado como premissa analítica por certas correntes da ciência política é observado na realidade exonera estudiosos(as) de levar em conta os complexos aspectos 
sociais e culturais estudados por outras abordagens. Trata-se de um solipsismo epistemológico que persiste na ciência política brasileira, mas que já foi superado até mesmo por autores(as) mais recentes da linhagem teórica de Downs. Em suma, o reconhecimento da relevância de fatores socioeconômicos e psicossociais no estudo do comportamento político aponta para a necessidade de entender a ciência política como uma sociologia da política (Reis, 2000b). Só assim será possível avançar no conhecimento e enfrentar de maneira efetiva os problemas concretos da política brasileira.

\section{Referências bibliográficas}

ACHEN, C.; BARTELS, L. Democracy for realists: why elections do not produce responsive government. Princeton: Princeton University Press, 2017.

ALDRICH, J.; MCKELVEY, R. "A method of scaling with applications to the 1968 and 1972 presidential elections". The American Political Science Review, vol. 71, no 1, p. 111-130, 1977.

ALmeIDA, A. "À esquerda dos números, à direita dos fatos". Insight Inteligência, vol. 15, p. 113-128, 2001.

AMARAL, O.; Ribeiro, P. "Por que Dilma de novo? Uma análise exploratória do Estudo Eleitoral Brasileiro de 2014". Revista de Sociologia e Política, vol. 23, n 56, p. 107-123, 2015.

AMES, B.; SMITH, E. "Knowing left from right: ideological identification in Brazil, 2002-2006". Journal of Politics in Latin America, vol. 2, no 3, p. 3-38, 2010.

AMES, B.; GaRCÍA-SÁnCHEZ, M.; SMITH, A. E. "Keeping up with the Souzas: social influence and electoral change in a weak party system, Brazil 2002-2006". Latin American Politics and Society, vol. 54, $\mathrm{n}^{\circ} 2$, p. $51-78,2012$.

AMES, B., et al. "The Brazilian Electoral Panel Studies (Beps): Brazilian public opinion in the 2010 presidential elections". IDB Working Paper no IDB-TN-508, 2013. Disponível em:

<https://publications.iadb.org/en/publication/12807/brazilian-electoral-panel-studies-beps>. Acesso em: 4 jun. 2019.

BAtista Pereira, F. "Sofisticação política e opinião pública no Brasil: revisitando hipóteses clássicas". Opinião Pública, vol. 19, no 2, p. 291-319, 2013.

. "Voto econômico retrospectivo e sofisticação política na eleição presidencial de 2002". Revista de Sociologia e Política, vol. 22, no 50, p. 149-174, 2014.

BATISTA Pereira, F.; Fuks, M.; CASAleCCHI, G. Sofisticação política e voto para presidente no Brasil. In: BonifÁCio, R.; CASALECCHI, G.; DeUs, C. (orgs.). O voto para presidente no Brasil: 1989 a 2010, condicionantes e fatores explicativos. Curitiba: Íthala, 2014.

BonifÁCio, R.; CASALECCHI, G; SANDES-FreitAS, V. E. V. Ideologia e voto nas eleições presidenciais brasileiras. In: BONIFÁCIO, R.; CASALECCHI, G.; DEUS, C. (orgs.). O voto para presidente no Brasil: 1989 a 2010, condicionantes e fatores explicativos. Curitiba: Íthala, 2014.

CARREIRÃo, Y. A decisão do voto nas eleições presidenciais brasileiras. Rio de Janeiro: Ed. FGV, 2002a.

2002b. "Identificação ideológica e voto para presidente". Opinião Pública, vol. 8, no 1, p. 54-79, 
FREDERICO BATISTA PEREIRA

. "A eleição presidencial de 2002: uma análise preliminar do processo e dos resultados eleitorais". Revista de Sociologia e Política, vol. 22, p. 179-194, 2004.

CARREIRÃO, Y. "Relevant factors for the voting decision in the 2002 presidential election: an analysis of the Eseb (Brazilian Electoral Study) data". Brazilian Political Science Review, vol. 1, no 1, p. 70-101, 2007.

CASTRO, M. "Determinantes do comportamento eleitoral - A centralidade da sofisticação política". Tese de Doutorado em Ciência Política. Iuperj, Rio de Janeiro, 1994.

CONVERSE. P. The nature of belief systems in mass publics. In: APTER, D. Ideology and discontent. New York: Free Press, 1964.

Cultura Política I. CESOP-DATAFOLHA/CEDEC/BRASL89. SET-00186 In: Banco de Dados do Centro de Estudos de Opinião Pública, Unicamp, Campinas, 1989. Disponível em:

<https://www.cesop.unicamp.br/por/banco_de_dados/v/421>. Acesso em: out. 2019.

Cultura Política III. CESOP-DATAFOLHA/CEDEC/BRASL90. MAR-00219. In: Banco de Dados do Centro de Estudos de Opinião Pública, Unicamp, Campinas, 1990. Disponível em:

<https://www.cesop.unicamp.br/por/banco_de_dados/v/458>. Acesso em: out. 2019.

Downs, A. An economic theory of democracy. New York: Harper and Row, 1957.

DRUCKMAN, J.; KAM, C. Students as experimental participants. In: DRUCKMAN, F., et al.

(orgs.). Cambridge handbook of experimental political science. Cambridge: Cambridge University Press, 2011.

ESEB 2002. CESOP-FGV/BRASIL- 2002/NOV-01838. In: Banco de Dados do Centro de Estudos de Opinião Pública, Unicamp, Campinas, 2002. Disponível em:

<https://www.cesop.unicamp.br/por/banco_de_dados/v/1762>. Acesso em: out. 2019.

ESEB 2006. CESOP-IPSOS/BRASIL-2006/NOV-02489. In: Banco de Dados do Centro de Estudos de Opinião Pública, Unicamp, Campinas, 2006. Disponível em:

<https://www.cesop.unicamp.br/por/banco_de_dados/v/1583>. Acesso em: out. 2019.

ESEB 2010. CESOP-VOXPOPULI/BRASIL-2010/NOV-02639. In: Banco de Dados do Centro de Estudos de Opinião Pública, Unicamp, Campinas, 2010. Disponível em:

<https://www.cesop.unicamp.br/por/banco_de_dados/v/1583>. Acesso em: out. 2019.

ESEB 2014. CESOP-IBOPE/BRASIL-2014/NOV-03928. In: Banco de Dados do Centro de Estudos de Opinião Pública, Unicamp, Campinas, 2014. Disponível em:

<https://www.cesop.unicamp.br/por/banco_de_dados/v/3716>. Acesso em: out. 2019.

FUKS, M.; BATISTA PEREIRA, F. "Informação e conceituação: a dimensão cognitiva da desigualdade política entre jovens de Belo Horizonte". Revista Brasileira de Ciências Sociais, vol. 26, no 76, p. 123$143,2011$.

GRANGER, C. "Investigating causal relationships by econometric models and cross-spectral methods". Econometrica, vol. 37, no 3, p. 424-438, 1969.

HOLZHACKER, D.; BALBACHEVSKY, E. "Classe, ideologia e política: uma interpretação dos resultados das eleições de 2002 e 2006". Opinião Pública, vol. 13, no 2, p. 283-306, 2007.

HOWELL, S. "Candidates and attitudes: revisiting the question of causality". The Journal of Politics, vol. 48, no 2, p. 450-464, 1986. 
NON CAUSA PRO CAUSA: O VOTO DE DIREITA E ESQUERDA NO BRASIL

IzUmi, M. "Ideologia, sofisticação política e voto no Brasil". Opinião Pública, vol. 25, no 1, p. 29-62, 2019.

KING, G. "Replication, replication". PS: Political Science and Politics, vol. 28, n 3, p. 444-452, 1995.

KING, G., et al. Designing social inquiry: scientific inference in qualitative research. New Jersey: Princeton University Press, 1994.

KROSNICK, J.; MiLBURN, M. "Psychological determinants of political opinionation". Social Cognition, vol. 8, no $^{\circ}$, p. 49-72, 1990.

KRosNick, J. A.; RAHN, W. "Attitude strength". Encyclopedia of Human Behavior 1.1, p. 279-289, 1994.

KUKLINSKI, J.; QUIRK, P. Reconsidering the rational public: cognition, heuristics, and mass opinion. In: LUPIA, A., et al. (orgs.). Elements of reason: cognition, choice, and the bounds of rationality, 2000.

LAVINE, H., et al. "The moderating influence of attitude strength on the susceptibility to context effects in attitude surveys". Journal of Personality and Social Psychology, vol. 72, no 2, p. 359-373, 1998.

LENZ, G. "Learning and opinion change, not priming: reconsidering the priming hypothesis". American Journal of Political Science, vol. 53, no 4, p. 821-837, 2009.

LUSKIN, R. From denial to extenuation (and finally beyond): political sophistication and citizen performance. In: KUKLINSKI, J. (org.). Thinking about political psychology. Cambridge: Cambridge University Press, 2002.

NicolaU, J. "Determinantes do voto no primeiro turno das eleições presidenciais brasileiras de 2010: uma análise exploratória". Opinião Pública, vol. 20, no 3, p. 311-325, 2014.

Oliveira, C.; TURGEON, M. "Ideologia e comportamento político no eleitorado brasileiro". Opinião Pública, vol. 21, no 3, p. 574-600, 2015.

Pimentel, J.; Russo, G.; Avelino, G. "Bolsonaro se diz de direita. E você?". Jota, 31 out. 2019. Disponível em: <https://www.jota.info/paywall?redirect_to=//www.jota.info/opiniao-eanalise/colunas/cepesp/bolsonaro-se-diz-de-direita-e-voce-31102019>. Acesso em: 1 out. 2019.

ReIS, F. "Identidade, política e teoria da escolha racional". Revista Brasileira de Ciências Sociais, vol. 3, n० 6, p. 26-38, 1988.

. "A razão do eleitor". Folha de S. Paulo, Caderno de Resenhas, p. 3, 9 set. 2000a.

Política e racionalidade: problemas de teoria e método de uma sociologia crítica da política. UFMG, Belo Horizonte, 2000b.

ReIS, F. W.; CASTRO, M. M. M. "Regiões, classe e ideologia no processo eleitoral brasileiro". Lua Nova, vol. 26, p. 81-131, 1992.

ReIS, F.; CASTRO, M. "Democracia, civismo e cinismo: um estudo empírico sobre normas e racionalidade". Revista Brasileira de Ciências Sociais, vol. 16, no 45, p. 25-46, 2000.

RENNó, L. "Information and voting: microfoundations of accountability in complex electoral environments". Tese de Doutorado em Ciência Política. University of Pittsburgh, Pittsburgh, 2004.

. "Os militantes são mais informados? Desigualdade e informação política nas eleições de 2002". Opinião Pública, vol. 12, no 2, p. 329-347, 2006. 
FREDERICO BATISTA PEREIRA

SCHLEGEL, R. "Educação e comportamento político: os retornos políticos decrescentes da escolarização brasileira recente". Tese de Doutorado em Ciência Política. USP, São Paulo, 2010.

SILVA, T. "Para além de esquerda e direita: a multidimensionalidade das crenças no Brasil contemporâneo (1989-2014)". Tese de Doutorado em Ciência Política. Universidade de Brasília, Brasília, 2017.

Singer, A. Esquerda e direita no eleitorado brasileiro. São Paulo: Edusp, 1999.

SNIDERMAN, P.; BRODY, R.; TETLOCK, P. Reasoning and choice: explorations in political psychology. New York: Cambridge University Press, 1991.

Spinelli, J. "A (im)pertinência da velha dicotomia: direita x esquerda". Cronos, vol. 1, no 2, p. 156$158,2000$.

Telles, H.; Storni, T. "Ideologia e valores: o voto dos eleitores de direita e esquerda". Revista Latinoamericana de Opinión Pública, vol. 1, no 1, p. 87-146, 2011.

ZECHMEISTER. E. Left-right identifications and the Latin American voter. In: CARLIN, R., et al. (orgs.), The Latin American voter: pursuing representation and accountability in challenging contexts. Ann Arbor: University of Michigan Press, 2015.

\begin{abstract}
Non causa pro causa: the left-right vote in Brazil

Most studies on voting behavior in Brazil agree that the left-right scale is not associated with vote choice. However, part of the scholarship often ignores or challenges such consensus. To solve this matter, this paper replicates and re-analyzes public opinion data used by studies that propose that voters choose candidates based on left-right positions (1989-2014). The results indicate that those studies present several methodological problems that invalidate their claims. The statistical relationship between ideology and voting is generally weak and only strong among a small group of sophisticated voters. Finally, panel data analysis does not find evidence that the statistical association reflects a causal relationship. All in all, it is time to search for new factors in the explanation of voting behavior in Brazil. Keywords: elections; ideology; political sophistication; voting behavior; survey analysis
\end{abstract}

\title{
Resumen
}

Non causa pro causa: el voto de derecha e izquierda en Brasil

La mayoría de los estudios sobre el voto en Brasil convergen en el diagnóstico de que la escala derechaizquierda no está asociada con la elección del candidato. Sin embargo, parte de las publicaciones a menudo ignora o cuestiona ese consenso. Para resolver este problema, este artículo reproduce y reanaliza los datos de opinión pública usados por estudios como evidencia de que el electorado votaría sí basado en la escala derecha-izquierda (1989-2014). Los resultados indican que estos estudios presentan varios errores metodológicos que invalidan sus conclusiones. La asociación estadística entre ideología y voto es generalmente baja y sólo alta entre un grupo reducido de votantes más sofisticados. Por último, el análisis de encuestas de panel no encontró evidencia de que la asociación estadística indique una relación causal. En resumen, es necesario buscar otros horizontes para explicar la decisión electoral.

Palabras clave: elecciones; ideología; sofisticación política; comportamiento electoral; análisis de encuestas 


\section{Résumé}

Non causa pro causa: le vote gauche et droit au Brésil

La majorité des études sur le comportement électoral au Brésil s'accordent à dire que l'échelle gauchedroit n'est associée au choix des voix. Cependant, une partie de la littérature ignore ou conteste ce consensus. Pour résoudre ce problème, cet article reproduit et analyse à nouveau les données d'opinion publique utilisées par les études qui proposent que les électeurs choisissent des candidats en fonction de leurs positions de gauche à droite (1989-2014). Les résultats indiquent que ces études présentent plusieurs problèmes méthodologiques qui invalident leurs affirmations. La relation statistique entre l'idéologie et le vote est généralement faible et seulement forte chez un petit groupe d'électeurs avertis. Enfin, l'analyse des données des groupes spéciaux ne permet pas de conclure que l'association statistique reflète une relation de cause à effet. En bref, el est temps de chercher de nouveaux facteurs dans I'explication du comportement électoral au Brésil.

Mots-clés: élections; idéologie; sophistication politique; comportement de vote; analyse d'enquête

Artigo submetido à publicação em 9 de julho de 2019. Versão final aprovada em 1 de julho de 2020.

Opinião Pública adota a licença Creative Commons CC-BY. 